Esta obra está bajo una Licencia Creative Commons Atribución-NoComercial-Compartirlgual 4.0 Internacional

\title{
Animales no humanos y suburbios de baja densidad
}

\author{
Non Human Animals and low-density suburbs
}

\author{
Pablo Frasson: pablofrasson@outlook.com \\ https://orcid/0000-0001-6149-1606 \\ Universidad Nacional de Rosario (Argentina)
}

\section{Resumen}

Este texto busca acompañar algunos procesos de deconstrucción de modelos de vinculación con el entorno, la naturaleza y la vida. Será, en este caso, la reflexión sobre cómo el suelo se transforma en mercancía y todo aquello que en su interior habita pierde su entidad libre, quedando sometido a la voluntad del dueño poseedor. Este texto recuerda la conceptualizaciónde las clausuras urbanas como forma novedosa de ocupación del suelo, desde la legitimidad humana a los intereses de los animales no humanos silvestres y liminales. Se toma el caso del suburbio como espacio de experimentación donde se materializan ideas de un posible urbanismo no especista, interesado en los animales y testigo, en algún caso, de un 
paradigma biocéntrico, ya no antropocéntrico. Por último, se analizan dos ejemplos en tanto constituyen o no genuinas formas de integración e inclusión entre humanos y no humanos.

Palabras clave: suburbio, urbanismo no especista, animales no humanos

\section{Abstract}

This text seeks to accompany some processes of deconstruction of models of linking with the environment, the nature and the life. It will be, in this case, the reflection on how its transformation into merchandising and all that in its interior dwells within its free entity, being sometimes due to the volunteer of its own possession. This text recovers the conceptualization of urban enclosures as a novelty form of occupation of the land, from human legitimacy to the interests of animals in wild and liminal humans. The case of the suburb is taken as a space for experimentation where ideas of a possible urbanism in the speciesist, interested in the animals and the testament, in some case of a biocentric paradigm, and in the anthropocentric. Finally, they analyze the examples and as such constitute the genuine forms of integration and inclusion between humans and humans.

Keywords: suburb, non-specific urbanism, non-human animals

La forma en que el hombre establece asentamientos está atravesada, siempre, por el sistema de valores e ideas que definen la relación entre quienes son considerados pares, quienes son considerados otros y aquello que es considerado una cosa. Quien detenta el poder configure la manera de construir la ciudad del presente, según aquella cosmovisión y estructura las formas de intervenir el suelo según las jerarquías que su mirada le presenta, definiéndose así un plano donde el límite es la estrella y la propiedad privada la galaxia sustrato de todo movimiento. En tal panorama y advirtiendo que las cosmovisiones van cambiando a través del tiempo, según conquistas de los pueblos o inclusive adaptaciones al sistema hegemónico, las ciudades absorben esos cambios, se reescriben sobre sí mismas. Hoy estamos escribiendo sobre ciudades y animals no humanos.

A su vez, este texto nace como una continuación de la conceptualización de clausuras urbanas, en tanto reflexión que pretende consolidar la presencia de los animales en lasciudades, no como recurso o deleite para las personas, sino según sus propios intereses. Es decir, este concepto no existe en el repertorio de los arquitectos y planificadores urbanos en tanto elemento que atienda los propios intereses de los animales. Tenemos zoológicos, 
reservas urbanas de flora y fauna, guarderías, ecoparques, etc, pero todos parten, en mayor o menor medida, de una mirada especista y antropocéntrica. El animal es y existe en tanto la supervision del humano. Cuando se conceptualiza la clausura urbana, se pretende la no invasión y el reconocimiento de la libertad e independencia de vida de quien existe antes que la urbanidad o de quien necesita para su calidad de vida ciertos espacios de privacidad o de distancia de los seres humanos o de otros animales no humanos. (Frasson, 2018)

Para enfatizar lo antes dicho vale hacer el ejercicio imaginativo de visualizar una porción de tierra que no ha sido urbanizada, o inclusive, una construcción humana que ha sido abandonada. Allí aparecen formas de vida de todo tipo, que estructuran su vivir con reglas aún en gran parte desconocidas por los humanos. El resultado, en tanto síntesis funcional a este artículo, es la convivencia y supervivencia de individuos, sin ayuda ni presencia humana directa.El problema empieza a ser problema en tanto ocurre una superposición de intereses en el mismo suelo físico, ahora devenido territorio por los múltiples procesos caracterizados y significados por los humanos. Entonces, cabe empezar a pensar: ¿Cómo convivimos entre diferentes, a partir del reconocimiento de la igualdad de derechos asociados a la dignidad básica humana y no humana?

Vale remarcar aquel tema introducido en las líneas anteriores, al solo efecto de dejar en claro que, así como en todo sistema político, económico y cultural, las personas humanas han sabido construir la defensa positiva de su nido íntimo como primera extensión material de supropio cuerpo, los animales han hecho algo semejante. Obviamente, desde su forma de interpretar sus propios cuerpos y aquello que los rodea. Podría pensarse aquí que los animales no han interpretado nada, sino que su forma de habitar es puramente instintiva. Personalmenteentiendo que este argumento es más de la misma visión antropocéntrica que nombró y clasificó las cosas desde su propia vivencia en la tierra. Pienso en Borges (1952) y en la enciclopedia china que se titula Emporio celestial de conocimientos benévolos. "En sus remotas páginas está escrito que los animales se dividen en a) pertenecientes al Emperador b) embalsamados c) amaestrados d) lechones e) sirenas f) fabulosos g) perros sueltos $h$ ) incluidos en esta clasificación i) que se agitan como locos j) innumerables k) dibujados con un pincel finísimo de pelo de camello l) etcétera $\mathrm{m}$ ) que acaban de romper el jarrón $\mathrm{n}$ ) que de lejos parecen moscas." Nunca fui un hornero (Furnarius rufus), y eso no impide que pueda entender que si el hornero sigue construyendo su vivienda como aparentemente lo hacían sus ancestros, es porque sigue él encontrando materia prima disponible para la construcción y las condiciones básicas necesarias para el desarrollo de su vida. O mejor dicho aún, porque el hornero hace su interpretación sensorial del entorno y construye su nido. Foucault dice que el sistema de clasificación expuesto en el ensayo de Borges es significativo, debido a la evidente 
imposibilidad de concebirlo, y porque evidencia la arbitrariedad de la manera cómo se clasifican las cosas (Foucault, 1973)

Nombrar un elemento urbano a partir de ahora disponible en el repertorio de los arquitectos y planificadores urbanos es el gesto inicial para pensar que los animales pueden vivir como venían viviendo con la garantía de intimidad, protección y vivienda que nunca antes les había sido reconocida.

Aquí quisiera evocar los aportes que Saskia Sassen hace, posicionándose en el borde del sistema, a las consideraciones sobre las lógicas que dominan el mundo, en tanto éstas son poderosísimas formas de impacto en los territorios. Vale este párrafo como un gran paréntesis al texto y como planteo multiescalar del asunto. Sassen expresa con rotunda claridad cómo la lógica que hoy domina la modernidad global dejó de ser la de la inclusión de las personas (como consumidores, consumidores como maquinaria y combustible de una cadena de producción y generación de riquezas concentradas), para pasar a una lógica de expulsión basada en la financialización de más sectores de la economía como forma de generar plusvalía sin necesidad personas de por medio. (Sassen, 2015). Esta fácil multiplicación de riquezas hace de la expulsion la principal consecuencia (2). Y, ¿cuál es la relación con los animales no humanos? En principio, si estás dinámicas avanzan y expulsan a humanos, mucho más expulsarán a animales no humanos.

A su vez, la ilimitada generación de riqueza sin un fin éticamente bueno pone en riesgos la vida de más y más individuos. La autora cita como ejemplo la compra de grandes extensiones de tierra en África por parte de estados o empresas privadas para plantar palma para su posterior producción de biocombustibles. Esa compra ejecutada con las riquezas de la financialización de la economía, trae consigo grandes expulsiones, no solo de poblaciones originarias, dueñas de esas tierras, sino también de flora y fauna. La fauna son esos animales sintientes que mueren porque su hábitat es devastado, y los que logran escapar y adaptarse, quedan en nuevo riesgo. Se suele decir que cada vez habrá más nuevos habitantes de ciudades o que las ciudades seguirán creciendo. La pregunta es, ¿de dónde salen esos nuevos habitantes, humanos y no humanos?

Son muchos los motivos que dan origen a nuevas urbanidades, los que se destacan podrían resumirse en una lista breve: la especulación inmobiliaria (algunas veces asociadas al blanqueo de capitales) y el crecimiento de la población (urbana, por adopción o por propio crecimiento demográfico) (3). En este artículo se intenta pensar cómo la ciudad, particularmente un modelo simple de ciudad, crece y se expande, bajo el leit motiv de vivir en mayor relación con la naturaleza, ya sea por los beneficios higienistas o por una cosmovisión romántica del paisaje. El borde de la ciudad vuelve a ser objeto de la mirada proyectual. Esta 
vez como sustrato de proyectos suburbanos de baja densidad. Se abordarán dos ejemplos, para evidenciar formas de ocupación del suelo, cómo las mismas pueden o no integrar a los animales no humanos.

Vale hacer una rápida caracterización del suburbio residencial como una manera de ocupar el suelo a través de la construcción de viviendas unifamiliares con jardines, en un marco "natural", donde predomina el vacío por sobre el lleno. El uso predominante es el residencial, con algunos equipamientos comerciales, educativos o de salud, siempre ponderando el espacio no construido por sobre el agregado edilicio. Estos suburbios tienen muchas manifestaciones a lo largo y ancho del mundo; la variable común suele ser la interdependencia con el automóvil y con alguna otra área de la ciudad (en general el centro). El consumo de energía, de productos y de servicios de mantenimiento atraviesa la vida cotidiana.

Me interesa instalar una premisa: consumir está íntimamente ligado al sufrimiento animaly modificar la forma de vivir en la ciudad puede contribuir a evitar ese sufrimiento. En tal sentido, traigo dos ejemplos de modelo suburbano. El primer ejemplo es el suburbio llamado Harmony, en Florida, Estados Unidos. Este suburbio representa el modelo hegemónico de construcción de hábitat de condición suburbana para los humanos. Muchos podrían ser los ejemplos, pero este en particular tiene sus adaptaciones a un público comprador "cada vez más exigente" con la calidad de vida de algunos animales, humanos y no humanos. Fue Jennifer Wolch quien tomó este asentamiento humano para estudiarlo según sus herramientas conceptuales, caracterizándolo como una zoopolis.(4) En la página web oficial (5) del emprendimiento pueden verse fotos, leerse textos e interpretarse planos generales que dan cuenta de una pretendida intención de reconocer la preexistencia de un hábitat natural donde animales con diferentes intereses habitan. Harmony sepresenta como un lugar de tranquilidad, comodidades y ciertas amenidades (cancha de golf, piscinas, lagos recreativos, etc) También se bridan algunas sugerencias e invitaciones para actividades sociales que poco integran a los animales no humanos en la vida cotidiana (directa o indirectamente) y están más asociadas a los placeres terrenales típicos humanos (comer, beber, recrearse en grupo). Eventualmente hay alguna propuesta de recorridos de expedición en la naturaleza, como actividad de deleite humano.

Quiero también decir que este modelo constituye un ejemplo para el análisis porque sueleasociarse la idea del suburbio verde al cuidado del medio por la simple foto de sus habitants rodeados de árboles y un lago. Eso lo hace digno de réplicas por todo el mundo, bajo la utilización de un ficcional paradigma verde, sostenible. Quisiera proponer pensar las ciudades en términos de procesos y no de fotos o de ciudad construida. Construir suburbios como Harmony supone reafirmar la dependencia con el uso del automóvil, la fabricación de 
asfalto, la construcción de grandes casas con materiales provenientes de la industria química, el consumo de grandes cantidades de productos para el mantenimiento diario y, sobre todo, gran cantidad de energía para el funcionamiento del barrio. Wolch, en su libro, se pregunta el por qué los animals importan en las ciudades, y allí mismo define e introduce el concepto de zoopolis. (Wolch, 1998).

Ella expresa: "Para permitir el surgimiento de una ética, una práctica y una política de cuidado de los animales y la naturaleza, debemos renaturalizar las ciudades e invitar a los animales a volver a encantar la ciudad. A esto lo llamo zoopolis. La reintegración de las personas con los animales y el medio ambiente, y el conocimiento de los animales y el medio ambiente" (p.124). En base a esta definición es que Wolch, analiza Harmony en el año 2009 (6) y la reconoce una zoopolis. La autora pondera algunos valores, como que las personas viven mejor cuando tienen contacto frecuente con animales y con la naturaleza, la conservación del medio, en tanto las generaciones futuras puedan acceder a los mismos recursos y la valoración por la cultura del reciclado, la reducción y la reutilización en pos de la disminución de generación de basura. El planteo es antropocéntrico y los animales son en tanto el hombre los necesita.

El otro modelo de suburbio es la Ecovilla Gaia en la provincia de Buenos Aires, Argentina. Se tomó este ejemplo con la doble intención de ejemplificar un modelo de ciudad posible, real,donde personas viven según una cosmovisión del mundo en torno a la valoración de la vida en todas sus formas, conscientes de la existencia de otros seres vivos con intereses diferentes. Este punto es clave, porque la idea estructura la forma de construir ciudad. (7) La ecovilla podría analizarse desde muchas miradas, mas me interesa poner énfasis en cómo esta forma de hacer ciudad y su sustento ideológico (diferente al sustento ideológico de Harmony), reducen el sufrimiento animal como consecuencia del diseño permacultural del hábitat. Según palabras de Bill Mollison, en el libro, Introducción a la Permacultura, “(...) la permacultura trata con plantas, animales, construcciones e infraestructuras (agua, energía, comunicaciones). Sin embargo, la permacultura no trata acerca de estos elementos en sí mismos, sino sobre las relaciones que podemos crear entre ellos por la forma que lo ubicamos en el paisaje." (p.5) Las construcciones son en su mayoría de adobe de tierra del mismo lugar, los techos de paja, maderas recicladas o del propio bosque (cultivado como estrategia de reducción de consumo). Los pisos de piedra, ladrillos o materiales reciclados, asimismo las ventanas y puertas.

No existe el asfalto, tampoco el automóvil como forma ordinaria de transporte. El abastecimiento de energía es a través de fuentes renovables, hay montes frutales plantados para producir alimentos y los habitantes llevan dietas vegetarianas. Más allá de que la escala del proyecto es pequeña, evidencia que estas otras alternativas de relacionarse con el medio son posibles. 
El uso de estos dos ejemplos, inclusive sin profundizar mucho en ellos, es para contraponer discursos y realidades. Quien lee los aportes de Wolch y Seymour sobre Harmony,bien podría imaginar una ecovilla como Gaia. En cambio, cuando se describe una ecovilla Gaia, Harmony es inviable. El objetivo principal de esta modesta y sintética comparación (puramente intencionada) es repensar cómo aquello que se nos presenta amigable con los animales puede no serlo y sobre todo, puede ser muy nocivo. Los suburbios residenciales de baja densidad estadounidenses del siglo XXI siguen sin adaptarse a nuevos paradigmas (antiespecistas). Pues el modelo económico que los respalda basa su existencia en la explotación ad infinitum de la naturaleza, incluidos los humanos.

Si nos retrotraemos 30 años atrás, era muy poco probable que en los grupos de pertenencia de cualquier persona hubiera alguien vegano o vegetariano. Sin embargo, si hoy mismo pensamos lo mismo, eso cambió. A su vez, hoy no pensamos que nuestras casas y nuestros barrios, calles y escuelas están montadas en sistemas constructivos, técnicas y materiales que explotan y hacen sufrir a los animales. Pensar en términos de procesos implica, en este caso de análisis crítico, desagregar cada instancia de trabajo, evaluándola según el sufrimiento, muerte y dolor que le genera a un tercero sintiente. Pensar el consumo en general en esos términos acompaña, no solo al advenimiento de un urbanismo no especista, sino una vida cotidiana igualitaria donde el sufrimiento es una opción y no un patrón inherente a la vida.

Notas

(1) Quiero aprovechar esta nota para aclarar que el estilo elegido de escritura para este artículo no responde a la predilección por un público lector especializado en arquitectura o urbanismo, sino a aquellos interesados en la temática del derecho animal y los estudios críticos animales en general. El presente texto pretende integrarse a la construcción colectiva del debate y del conocimiento.

(2) La autora reconoce que su planteo es heurístico, posicionándose en un extremo de la realidad aún no desarrollada en su máxima expresión.

(3) Siguiendo aquella referencia de Sassen sobre cómo en un momento de desarrollo insdustrial y de producción de bienes los humanos eran necesarios (en tanto consumidores o mano de obra) podría preguntarme también si la expansión de las ciudades, es, en algunos casos, producto de esa misma lógica de aparente inclusión.

(4) En el año 1998, Jennifer Wolch y Jody Emel editan un libro llamado Animal Geographies, place, politics, and identity in the nature-culture borderlands. Allí, en el capítulo VI, Jennifer Wolch usa el término Zoopolis y lo caracteriza. En el año 2011, Sue Donaldson y Will Kimlicka 
publican el libro Zoopolis,a political theory of animal rights. Esta nota pretende aclarar, pues en el presente el término zoopolis se lo asocia a los aportes de Donaldson y Kimlicka, mas en este texto se referencia el uso que le dio Jennifer Wolch. Ambos abordajes son valiosos y merecen su atención.

(5) http://harmonyfl.com/

(6) El analisis queda expreso en un paper de diciembre de 2009 llamado "Toward Zoopolis?" realizado con la coautoría de Mona Seymour.

(7) Aquí uso la palabra ciudad, más allá de que la ecovilla se trate de un caso aislado. Elijo usar la palabra ciudad porque el proyecto contiene edificios construidos, de diferentes funciones, un trazado con caminos de comunicación y reglas que organizan las relaciones entre los elementos. Asimismo, se entiende por ciudad a la sumatoria de lo construido más las personas que en eso construido viven. Todo eso existe en Gaia.

\section{Bibliografía}

Borges, J. (1997). Otras inquisiciones. Madrid, España: Alianza.

Corboz, A., (2001), Le territoire comme palimpseste et autres essais, Paris, Francia: Les éditions de l'imprimeur

Frasson, P., (Enero-Junio2018), Clausuras urbanas y hábitat digno para animales no humanos silvestres y liminales, Revista LECA, Recuperado de:

http://revistaleca.org/journal/index.php/RLECA/issue/view/10/showToc

Mollison, B., (1994), Introducción a la Permacultura, Tasmania, Australia:Tagari

Foucault, M. \& Frost, E. (2011), Las palabras y las cosas : una arqueología de las ciencias humanas, Buenos Aires, Argentina: Siglo Veintiuno Editores Argentina

Sassen, S. \& Mastrangelo, S., (2015), Expulsiones : Brutalidad y complejidad en la economía global, Móstoles-Madrid, España: Katz Editores

Wolch, J., \& Emel, J.,(1998), Animal geographies, place, politics and identity in the natureculture

borderlands, Londres, Reino Unido: Verso 